\title{
Effect of Prior Austenite Grain Size Refinement by Thermal Cycling on the Microstructural Features of As-Quenched Lath Martensite
}

\author{
JAVIER HIDALGO and MARIA JESUS SANTOFIMIA \\ Current trends in steels are focusing on refined martensitic microstructures to obtain high \\ strength and toughness. An interesting manner to reduce the size of martensitic substructure is \\ by reducing the size of the prior austenite grain (PAG). This work analyzes the effect of PAGS \\ refinement by thermal cycling on different microstructural features of as-quenched lath \\ martensite in a $0.3 \mathrm{C}-1.6 \mathrm{Si}-3.5 \mathrm{Mn}(\mathrm{wt} \mathrm{pct})$ steel. The application of thermal cycling is found to \\ lead to a refinement of the martensitic microstructures and to an increase of the density of high \\ misorientation angle boundaries after quenching; these are commonly discussed to be key \\ structural parameters affecting strength. Moreover, results show that as the PAGS is reduced, \\ the volume fraction of retained austenite increases, carbides are refined and the concentration of \\ carbon in solid solution as well as the dislocation density in martensite increase. All these \\ microstructural modifications are related with the manner in which martensite forms from \\ different prior austenite conditions, influenced by the PAGS.
}

DOI: $10.1007 / \mathrm{s} 11661-016-3525-4$

(C) The Author(s) 2016. This article is published with open access at Springerlink.com

\section{INTRODUCTION}

LATH martensite is a key constituent of many advanced high strength steels such as martensitic steels, dual-phase (DP) steels, and other multi-phase steels like low-alloyed transformation-induced plasticity and quenching and partitioning steels. Many efforts are devoted to understand these microstructures and their effects on the mechanical properties. Prior austenite grain size (PAGS), steel compositions and processing routes play an important role in the formation and characteristics of lath martensite. However, there is not a clear explanation yet of how the PAGS affects martensite formation and consequently the resulting microstructures.

To understand the effect of the reduction of PAGS on the martensitic microstructure, it is important to have a clear picture of how martensitic microstructures are sub-divided. Lath martensite shows a hierarchical sub-grain structure comprising packets, blocks, subblocks, and laths of particular crystallography, ${ }^{[1,2]}$ as schematically illustrated in Figure 1(a). The lath is the fundamental crystallographic unit of martensite. The Kurdjumov-Sachs $(\mathrm{K}-\mathrm{S})$ orientation relation between parent austenite and lath martensite predicts that 24 unique crystallographic lath variants may develop from a single parent austenite grain. Laths align parallel to

JAVIER HIDALGO, Postdoctoral Researcher, and MARIA JESUS SANTOFIMIA, Associate Professor, are with the Department of Materials Science and Engineering, Delft University of Technology, Mekelweg 2, $2628 \mathrm{CD}$, Delft, The Netherlands. Contact e-mail: J.HidalgoGarcia@tudelft.nl

Manuscript submitted January 25, 2016.

Article published online May 5, 2016 each other to form blocks which consist of a pair of different variants. Parallel blocks that have a common habit plane with a PAG arrange in packets.

A number of papers have studied the effect of PAGS on the morphology and mechanical properties of lath martensite. ${ }^{[3-7]}$ Packet and block sizes are commonly observed to be reduced with a reduction of PAGS. ${ }^{[3]}$ This implies an increase of high-angle boundaries in as-quenched martensite microstructure, which are effective barriers to dislocation movement during deformation of lath martensite and strongly affect the strengthening of the material. ${ }^{[3,7-9]}$

PAGS reduction has other consequences for the martensitic microstructure. It leads to a reduction of the Ms temperature ${ }^{[10,11]}$ and may also cause an increase of the retained austenite (RA) fraction. Hui ${ }^{[5]}$ reported an increase of RA fraction as PAGS was refined in a $42 \mathrm{CrMoVNb}$ as-quenched steel subjected to a rapid cycling heat treatment. This observation can have important consequences for the mechanical response. Maresca et al. ${ }^{[12]}$ suggest that even a small fraction of interlath RA can enhance the deformation of microstructures based on lath martensite.

Moreover, changes of dislocation density and carbon distribution through the microstructure (in solution or forming carbides) may occur as a consequence of PAGS reduction by thermal cycling. Kennett et al. ${ }^{[13]}$ observed that as PAGS decreases, the dislocation density of martensite increases, as well as its measured micro-hardness.

An interesting method for PAGS reduction and thus microstructure reduction even to submicron scale $^{[3,4,6,14-16]}$ is the employment of a successive martensite-austenite reversion processes through rapid heating and quenching. However, there is a lack of investigations that methodically study the effect of 
PAGS reduction by thermal cycling on the microstructure of lath martensite. Apart from the formermentioned implications of PAGS reduction, block orientations, which have an important role in mechanical response, ${ }^{[8]}$ can be modified by thermal cycling and aligned in preferential directions. ${ }^{[6]}$

The present work explores the process of thermal cycling as a method to reduce PAGS and analyze further formation of lath martensite upon quenching. In this research, a $0.3 \mathrm{C}-1.5 \mathrm{Si}-3.5 \mathrm{Mn}$ steel was subjected to different heat treatments consisting of subsequent rapid austenitizing and quenching thermal cycles in order to reduce the PAGS. The effect of PAGS reduction on the size of blocks and packets, dislocation density, carbon distribution, and RA fraction was thoroughly investigated. Those microstructural features were analyzed by a combination of different techniques such as scanning electron microscopy (SEM), electron backscatter diffraction (EBSD), X-ray diffraction (XRD), and vibrating sample magnetometer (VSM). The observed microstructural modification was related with the manner in which martensite forms from austenite with different PAGS.

\section{EXPERIMENTAL PROCEDURE}

A $0.3 \mathrm{C}-1.6 \mathrm{Si}-3.5 \mathrm{Mn}$ (wt pct) steel was used in the present study. The 4-mm-thick steel sheets were received in the hot-rolled condition and the microstructure consisted of martensite with a RA fraction of approximately 0.05. Cylindrical specimens, with a length of $10 \mathrm{~mm}$ and a diameter of $3.5 \mathrm{~mm}$, were machined parallel to the rolling direction of the sheets. They were subjected to a set of four different heat treatments in a Bähr DIL 805 A/D dilatometer. These consisted of one or several rapid full austenitizing and quenching processes, as detailed in Figure 1(b). The specimens were named Cycle $X$, where $X$ refers to the number of applied consecutive cycles $(X=1, \ldots, 4)$. The Ms temperature was determined following the 1 pct offset method proposed by Yang and Bhadeshia ${ }^{[17]}$ and using fitting for non-linear FCC and BCC lattice thermal expansion according to Van Bohemen. ${ }^{[18]}$

A LakeShore 7307 VSM was used to determine RA fractions, $f_{\gamma}$. The samples were disk-shaped with a diameter of 3.5 and 2-mm thickness. A standard NIST nickel specimen was used to calibrate the VSM. The procedure followed is derived from the method described in Reference 19.

Specimens of each heat treatment were metallographically prepared for EBSD and SEM observation with a final polishing step of $0.05 \mu \mathrm{m}$ using an OPS suspension for 30 minutes. The SEM study was made after etching with 2 pct Nital, using a JEOL JSM-6500F field emission gun scanning electron microscope (FEG-SEM) operating at $17 \mathrm{kV}$. Orientation imaging microscopy (OIM) was performed on a FEI Nova600 Nanolab dual-beam (focused ion-beam) scanning electron microscope equipped with a FEG column. The analyses were carried out under the following conditions: acceleration voltage of $20 \mathrm{kV}$; working distance of $25 \mathrm{~mm}$; tilt angle

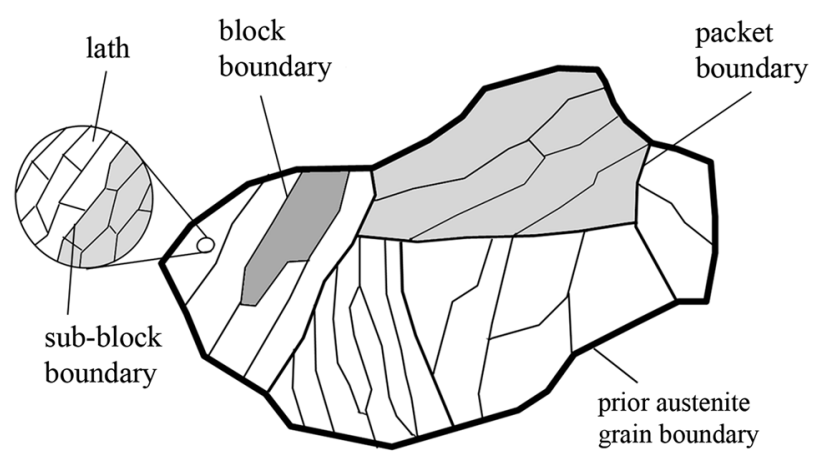

(a)

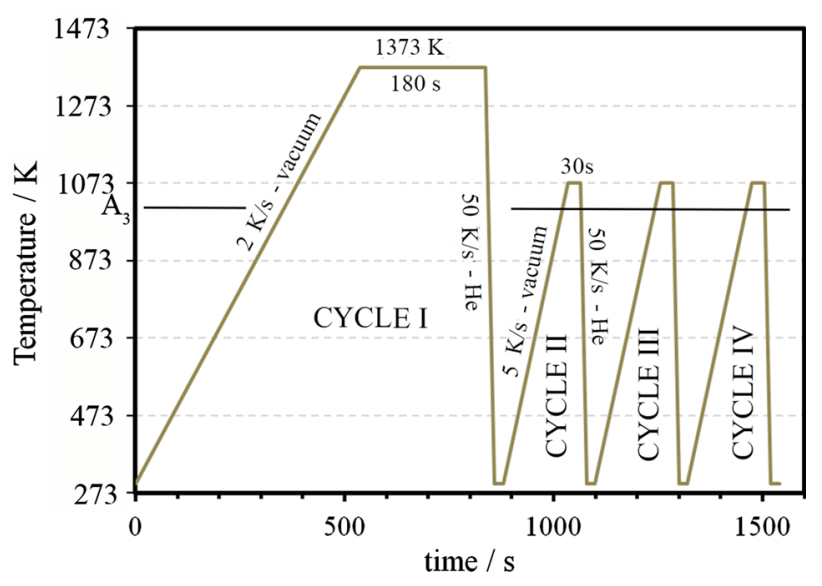

(b)

Fig. 1-(a) Schematic illustration showing the hierarchical structure of lath martensite. (b) Illustration representing the applied thermal cycles and heat treatment conditions.

of $70 \mathrm{deg}$; and step size of $50 \mathrm{~nm}$. Depending on the sample, several scans were made to cover a minimum of around 100 PAG. The orientation data were post-processed with the TSL software.

Grain substructures were resolved by interpretation of EBSD maps. In order to facilitate PAGS identification, clean-up was made by applying neighbor orientation correlation and grain dilatation tools of the OIM software. For the analysis of other microstructural features, the clean-up was avoided. After proper identification, the dimensions of these substructures were measured and statistics of the characteristic size were obtained. In the present work, the linear intercept method $^{[20]}$ was used to measure sizes of the PAGS and packets (PS). Equidistant horizontal and vertical lines were drawn (500 using OIM software) and the resulting mean intercept sizes of each line were averaged. The block width (BW) was estimated by drawing misorientation profile lines along multiple clusters of parallel blocks. These profile lines follow the direction of the BW. More than 100 blocks were consider to have a mean value.

X-ray diffraction experiments were performed using a Bruker type D8-Advance diffractometer in Bragg-Brenato geometry and a Lynxeye position sensitive detector using a $\mathrm{Cu}$ anode. Measurements were performed in the angular range of $38 \operatorname{deg}(2 \theta)$ to $145 \operatorname{deg}(2 \theta)$ with a step 
size of $0.03 \mathrm{deg}$ and counting time of $1 \mathrm{~s}$. The base line of the XRD profile was removed. Then $\mathrm{K}_{\alpha 2}$ elimination was performed and the intensity was corrected for the Lorentz Polarization factor. ${ }^{[21]}$ In the present work, linear least squares combined with Cohen method ${ }^{[22]}$ is used to obtain the mean value of martensite lattice parameter, $a_{\mathrm{BCC}}$, that minimizes the effect of random error in the measurements. Modified Williamson-Hall plots were employed for the estimation of the dislocation density from X-ray profiles as described in Reference 23. Reference values were obtained by XRD measurements on a Cycle I specimen that was annealed just below the intercritical region and subsequently quenched, with the aim of obtaining a relaxed $\mathrm{BCC}$ lattice (i.e., with minimum dislocation density) in which most of the carbon is in cementite carbides.

Vickers $1 \mathrm{~kg}$ micro-hardness was measured with a Struers Durascan tester over the cross section of the dilatometry sample to determine the effect of microstructure in hardness and support the discussion of the results.

\section{RESULTS}

\section{A. Grain Substructures Size and Boundary Density}

Assuming a $\mathrm{K}-\mathrm{S}$ orientation relationships between parent austenite and martensite, the misorientation associated with martensite boundaries varies from around $10 \mathrm{deg}$ to $20 \mathrm{deg}$ and $47 \mathrm{deg}$ to $57 \mathrm{deg}$ in the case of packets, and from around $50 \mathrm{deg}$ to $60 \mathrm{deg}$ in the case of blocks. ${ }^{[2]}$ Hence, it can be presumed that misorientations in the gap between these are due to boundaries corresponding to former austenite grains. These misorientation values are used as threshold values. Some parent austenite grain boundaries may have misorientation angles above and below these values, which may result in a slight overestimation of the grain size.

Figure 2 shows EBSD maps of different cycles combining image quality map and inverse pole figure. Boundaries presumably corresponding to PAG (misorientation between $20 \mathrm{deg}$ to $47 \mathrm{deg}$ ) are emphasized with white lines. Superimposed inverse pole map of Cycle I
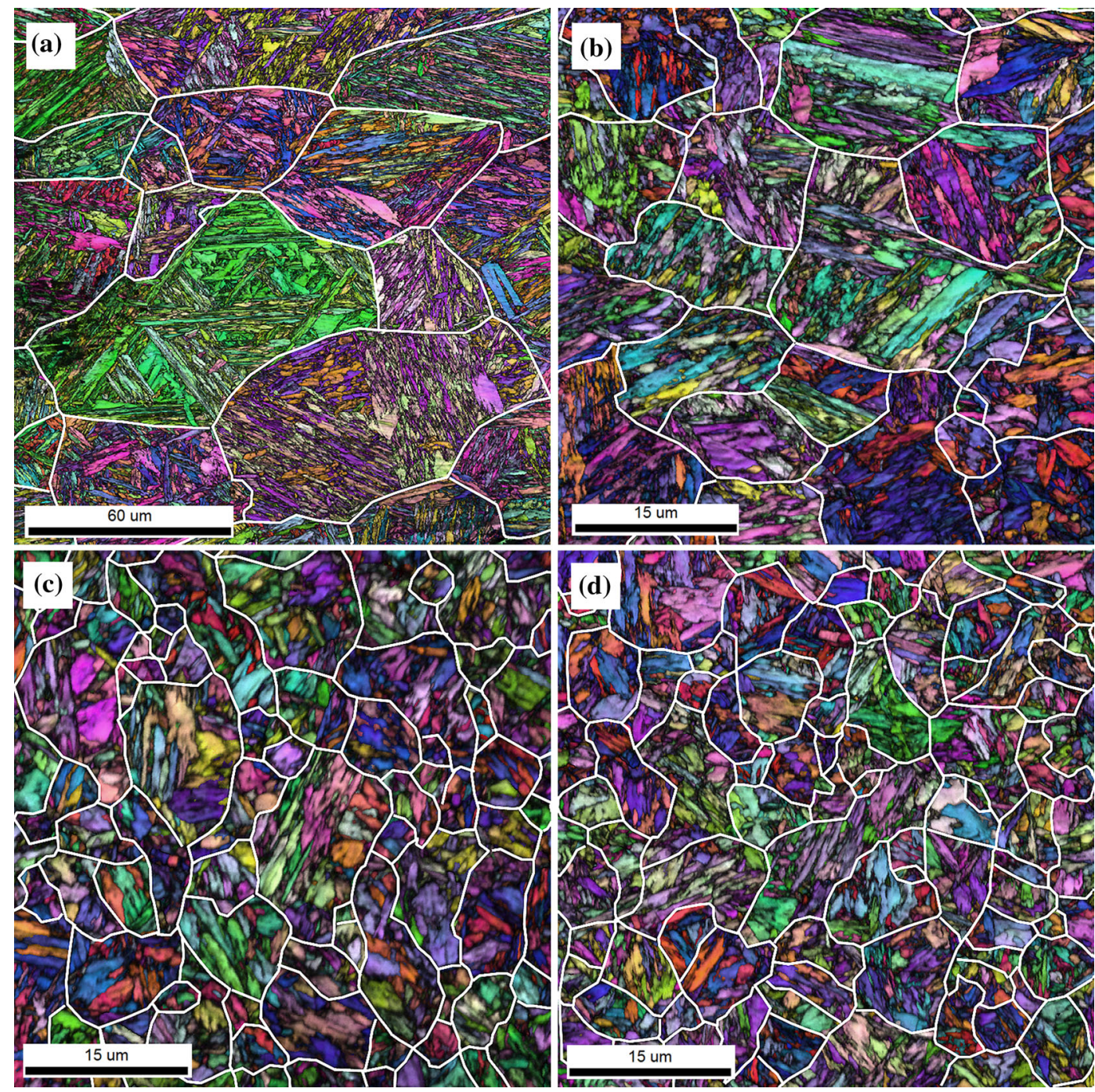

Fig. 2-Combined EBSD image quality and inverse pole figure for (a) Cycle I, (b) Cycle II, (c) Cycle III, and (d) Cycle IV. White lines represent misorientation of rotating angle between $20 \mathrm{deg}$ and $47 \mathrm{deg}$ most likely highlighting prior austenite grain boundaries (Color figure online). 


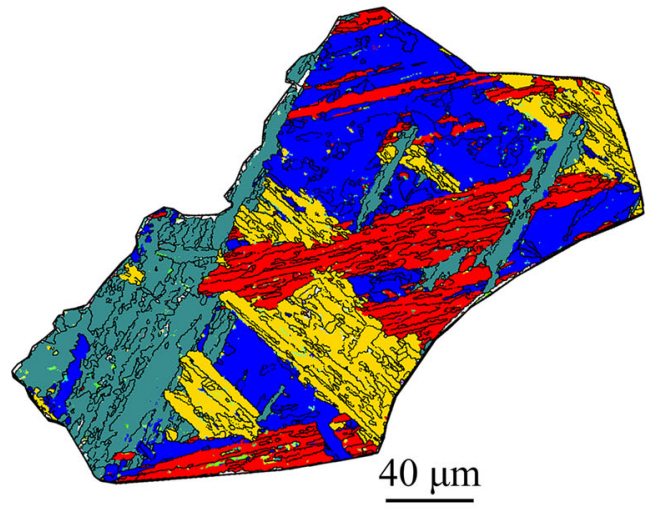

(a)

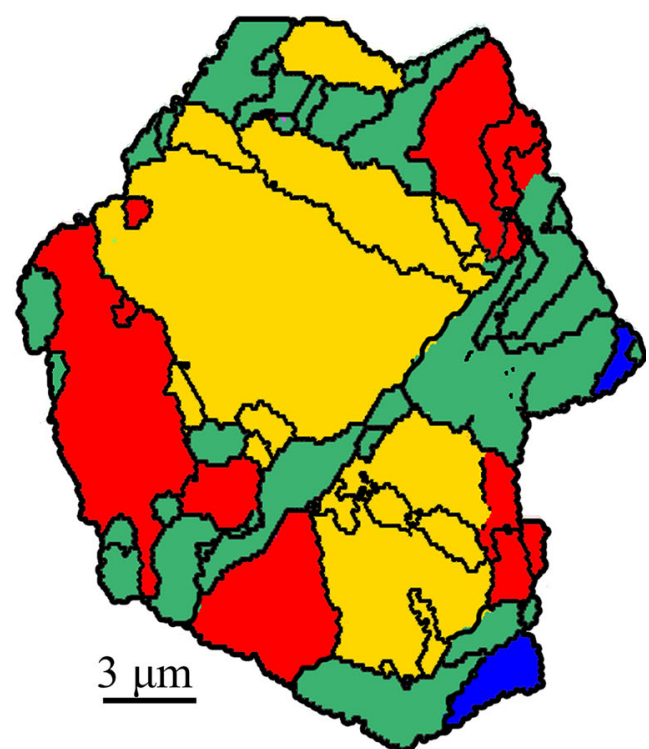

(c)

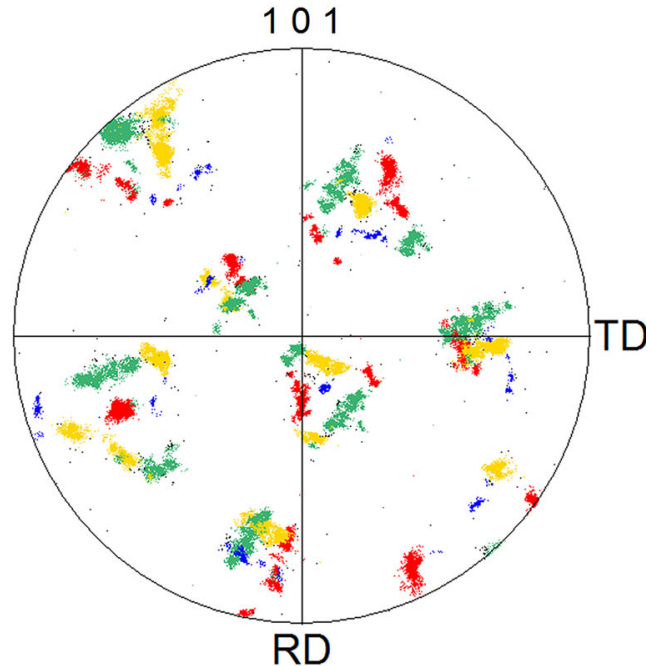

(d)

Fig. 3- (a) and (c) represent, respectively, a crop of a coarse (Cycle I) and a fine (Cycle IV) austenite grain in which packets sharing the same habit plane are tinted in different colors. Black lines are grain boundaries having a misorientation angle higher than 10 deg. $(b)$ and $(d)$ represent experimental $\langle 101\rangle_{\alpha}$ pole figures containing martensite crystal orientations inside (a) and (c) austenite grains, respectively (Color figure online).

Table I. Results of Grain Substructure Sizes and the Error of the Mean (PAGS: Prior Austenite Grain Size; PS: Packet Size; BW: Block Width)

\begin{tabular}{|c|c|c|c|c|c|c|c|c|c|c|c|c|}
\hline \multirow[b]{2}{*}{$(\mu \mathrm{m})$} & \multicolumn{3}{|c|}{ Cycle I } & \multicolumn{3}{|c|}{ Cycle II } & \multicolumn{3}{|c|}{ Cycle III } & \multicolumn{3}{|c|}{ Cycle IV } \\
\hline & PAGS & PS & BW & PAGS & PS & BW & PAGS & PS & BW & PAGS & PS & BW \\
\hline Mean & 80 & 18.6 & 1.15 & 14.1 & 7.4 & 0.69 & 10.3 & 5.4 & 0.65 & 9.2 & 5.2 & 0.52 \\
\hline Error & 4 & 0.8 & 0.07 & 0.8 & 0.4 & 0.04 & 0.4 & 0.2 & 0.05 & 0.8 & 0.2 & 0.06 \\
\hline
\end{tabular}

specimen (Figure 2(a)) shows that blocks within the parent austenite grains share similar orientations. This fact tends to disappear in other specimens, where grain substructure orientation becomes more dissimilar (Figures 2(b) through (d)). Those maps also show a break-up of the alignment of blocks in packets within the PAGS accentuated as the PAGs is reduced. This is clearly shown in Figure 3, which compares two different PAGs of different size from Cycle I and Cycle IV, respectively. Packets sharing blocks of a common habit 


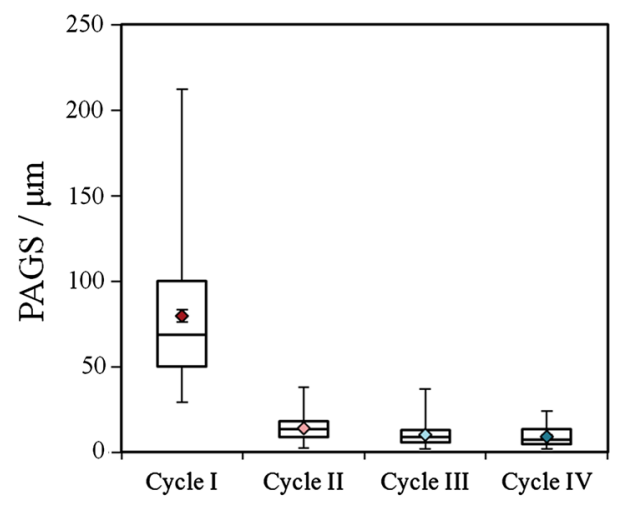

(a)

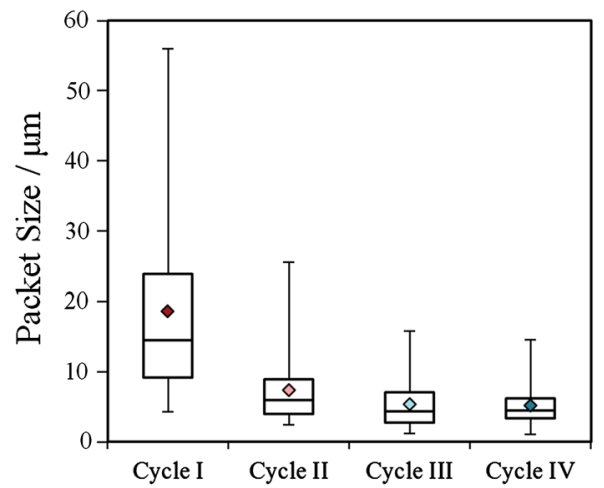

(b)

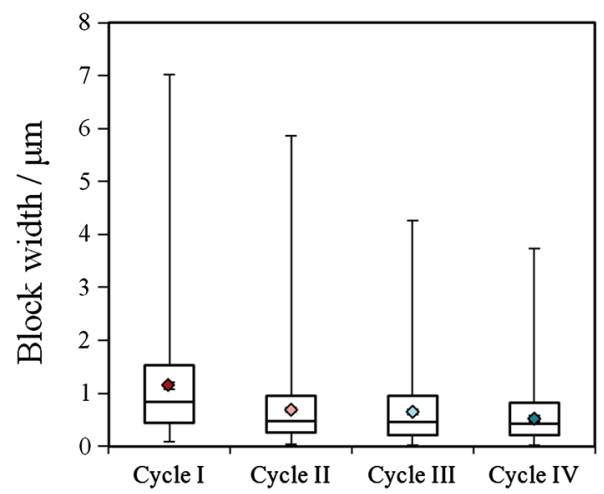

(c)

Fig. 4-Box and whisker plots showing the distribution of the different grain substructures: $(a)$ PAGS, $(b)$ PS, and $(c)$ BW. The extremes of the box represent the first and third quartiles and the divisor line is the median. Lower and upper whiskers correspond, respectively, with the minima and maxima values of the dataset. Diamond markers indicate the mean value and the error in the mean.

plane are colored in different tints and black lines delimit blocks. In coarse parent austenite grains, packets and blocks are elongated, whereas in fine grains, they tend to develop in a round shape.

Results of mean PAGS, packet size (PS), and BW obtained through different cycles are summarized in Table I. The size distributions, plotted by means of box, and whisker plots are shown in Figure 4. The PAGS is strongly reduced between Cycle I and Cycle II, and this reduction is less pronounced in subsequent cycles, obtaining similar values in Cycle III and Cycle IV. As PAGS is refined, PS also decreases. The ratios between the average PAGS and PS ( $\left.d_{\mathrm{PAGS}} / d_{\mathrm{PS}}\right)$ take the values of $4.3 \pm 0.3,1.9 \pm 0.1,1.9 \pm 0.1$, and $1.8 \pm 0.2$, respectively, from Cycle I to Cycle IV. The ratios approach unity in subsequent cycles, which is a theoretical limit since martensite laths do not grow crossing parent austenite boundaries. Parent austenite grains of around $1 \mu \mathrm{m}$ size and consisting of a single packet became frequent in Cycle III and Cycle IV specimens. Nonetheless, even for these fine grains, subdivisions in to several packets are still observed. Grains consisting of a single block were not observed. A slight reduction of BW with reduction of PAGS occurred.

The number of variants per parent austenite grain is reduced with the number of cycles as the PAGS is refined. Figures 3(b) and (d) show experimental $\langle 101\rangle_{\alpha}$ pole figures, containing martensite crystal orientations inside a coarse and a fine austenite grain, respectively. The observed symmetries are typically due to $\mathrm{K}-\mathrm{S}$ orientation relationships. ${ }^{[25]}$ Both figures do not show sharp dots (i.e., intensity maxima) as could be expected with well-defined variant orientations. This can be explained by plastic deformation of the parent austenite. Coarse austenite grains show approximately equal numbers of all 24 variants, while fine grains show fewer variants. This tends to be accentuated as PAGS is reduced to a few micrometer.

The prior austenite, packet, and block size distributions become more homogeneous upon increasing the number of cycles. In general, the width of the size distribution of the different subunits is large. Nonetheless, especially from Cycle II, most grains have a size reasonably close to the mean value, but outliers that considerably deviate from the interquartile range are always present.

Reduction of martensite grain substructures inherently leads to an increase of the grain boundary density. To account for the boundary density of different misorientation angles, the total length of boundaries (in 2D EBSD micrographs) showing a misorientation angle within a certain range was divided by the total area of EBSD scan. Grain boundaries less than 5 deg are discarded due to uncertainties in the measurement. The results of boundary density of different cycles are plotted in Figure 5a. The density of boundaries with high misorientation (47 deg to $60 \mathrm{deg}$ ) increases with the cycles, in correspondence with the reduction of grain substructures. Figure 5(b) shows the cumulative curves of misorientation angles. For values higher than approximately $60 \mathrm{deg}$, the cumulative of the boundary density represents the total grain boundary density accounting blocks, packets, and PAGS boundaries. It can be seen that the total grain boundary density increases with the cycles. If Cycle III and Cycle IV are compared, differences in the curves are only significant at angles around $60 \mathrm{deg}$, indicating that although PAGS and PS are similar, there is a reduction of block size as shown in Table I.

\section{B. Ms and Retained Austenite}

Figure 6(a) shows that the martensite start temperature $\left(M_{\mathrm{S}}\right)$ decreases with the number of cycles, 


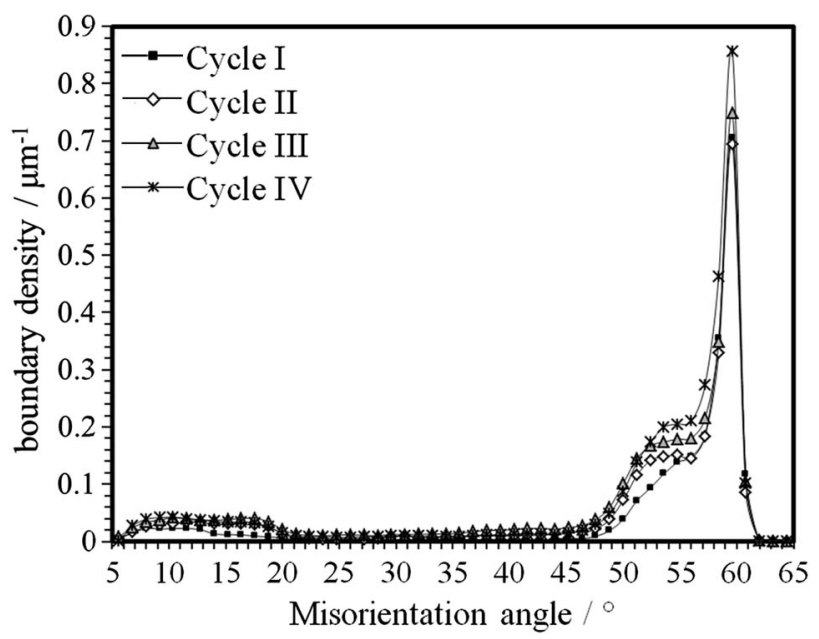

(a)

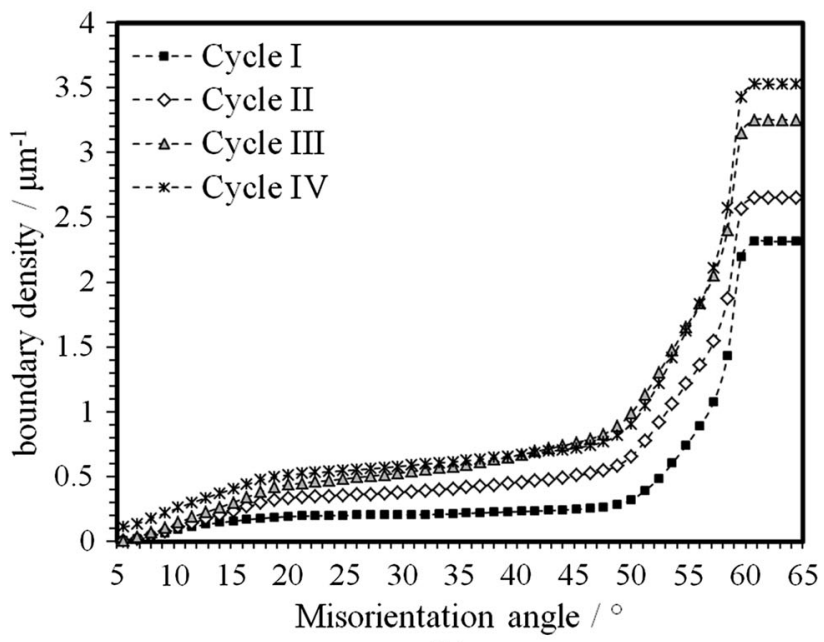

(b)

Fig. 5-Density of boundaries for different cycles (a) for specific misorientation angle intervals; 50 bins from 5 deg to 65 deg and (b) cumulative curves from $5 \mathrm{deg}$ to $65 \mathrm{deg}$.

influenced by the reduction of PAGS. A decrease of $17 \mathrm{~K}\left(17^{\circ} \mathrm{C}\right)$ with respect Cycle I was measured for the Cycle II. The reduction from Cycle II to Cycle III was $11 \mathrm{~K}\left(11^{\circ} \mathrm{C}\right)$ and it was $2 \mathrm{~K}\left(2^{\circ} \mathrm{C}\right)$ from Cycle III to Cycle IV. The decrease of Ms was relatively smooth from Cycle I to Cycle II considering the large reduction of PAGS. It becomes more pronounced as the grain size reduces to a few micrometer in subsequent cycles.

Unlike EBSD and XRD measurements, which are taken from the surface, VSM results represent a volumetric average, and magnetometry is considered a more reliable method to measure RA fractions. Figure 6(a) also shows the fraction of RA obtained by magnetometry plotted vs PAGS. The RA fraction increases with the number of cycles and seems to follow the inverse behavior with PAGS, when compared to $M_{\mathrm{S}}$.

Figure 6(b) shows an EBSD phase map of Cycle II specimen in which austenite was identified in sites corresponding to blocks and packet boundaries, in fractions up to 0.05 . The small size of the identified austenite grains and the low confidence index indicates an overestimation in the quantification of austenite fractions, especially considering VSM results. Nevertheless, $\mathrm{K}-\mathrm{S}$ orientation relationships of austenite with neighboring martensite are observed, which confirms the presence of austenite. In the XRD diffractogram, a very slight increase in intensity where the $\{220\} \gamma$ reflection theoretically occurs and slight asymmetry of $\{110\}_{\alpha}$ peak are the only indication of austenite phase, which is in agreement with the small fractions of RA obtained by VSM.

\section{Dislocation Density}

Figure 7(a) shows measurements of the crystalline domain size $(D)$ and dislocation density $\left(\rho_{\mathrm{XRD}}\right)$ after the application of the modified Williamson-Hall method to XRD diffractogram. According to literature,${ }^{[4]}$ martensite lath dimensions are not expected to vary extensively with PAGS. Therefore, the contribution of lath boundary to $\rho_{\mathrm{XRD}}$ is considered similar in all specimens. The obtained dislocation density values are within the same order of magnitude of $10^{15} \mathrm{~m}^{-2}$, but increase with the number of cycles. $D$ decreases with the number of cycles.

Dislocation density values obtained by XRD represent a macroscopic average. However, for martensitic steels, the dislocation density varies from place to place within grains on a microscopic scale. ${ }^{[26]}$ The substructure of quenched lath martensite contains high densities of entangled dislocations, reflecting the lattice invariant deformation and volume accommodation effects during athermal transformation from austenite. ${ }^{[27]}$ The kernel average misorientation (KAM) maps in EBSD analysis visualize short-range orientation gradients within individual grains. Local changes in the lattice orientation reflect lattice curvature that can be associated with geometrically necessary dislocations (GNDs). ${ }^{[28,29]}$ These are formed due to storage of dislocations associated with nonhomogeneous (non-uniform) deformation. In such a situation a shear gradient is created that gives rise to a lattice rotation and a net Burgers vector of a set of dislocations. In contrast, individual dislocations or dislocation arrangements (tangles, dipoles, multipoles, etc.) with a net Burgers vector of practically zero ${ }^{[29]}$ will not give rise to a significant rotation of the lattice and will not be detected by KAM. These last are also termed as statistically stored dislocations (SSDs)

Figure 8 shows KAM maps of as-quenched specimens. PAGs boundaries are indicated with black lines. Orientation gradients of up to $5 \mathrm{deg}$ are observed within the microstructure. Blocks, especially those standing out from the rest due to a relatively larger size, show almost no local lattice distortion in the core. In general, misorientations between $1.5 \mathrm{deg}$ to $2.5 \mathrm{deg}$ are measured near the block boundaries. The highest misorientations, close to $5 \mathrm{deg}$, always appear close to the grain boundaries and in regions in which FCC was indexed. Straight or curved contours are frequently outlined from the core of the blocks. Core regions, having low misorientations, can be linked to areas with SSDs dislocations, whereas the contours are most likely indicating cells of GNDs. Some blocks show predominantly misorientations in the order of $2.5 \mathrm{deg}$, 

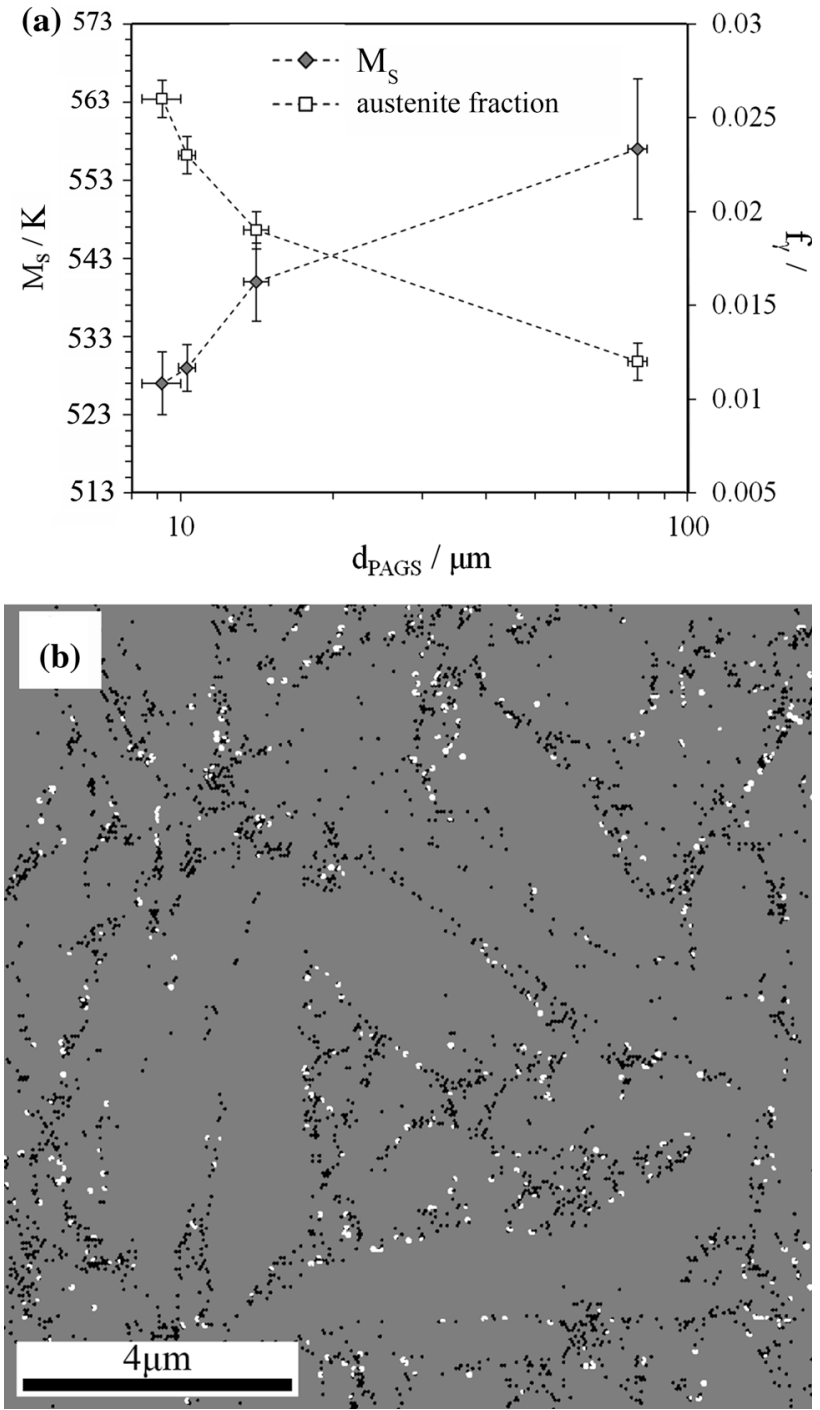

Fig. 6- (a) Variation of $\boldsymbol{M}_{\mathbf{S}}$ and retained austenite fractions with the PAGS. (b) Phase map of Cycle II specimen showing BCC (light gray) and FFC (black) phases. White lines represent FCC phase boundaries fulfilling the $\mathrm{K}-\mathrm{S}$ orientation relation with parent $\mathrm{BCC}$ phase.

suggesting that high strain gradients have been developed and more GNDs were stored in these locations. These observations suggest the nucleation and growth of martensite laths with preferential variants with apparently less restrictions, covering longer distances within the parent austenite grain compared to other variants. Comparing different cycles it can be established that this fact is less common in subsequent cycles, but there are some grains in which it can be observed even after several cycles. It seems that the number of these preferential substructures per PAG decreases as the PAGS is refined. The changes in tonalities as the PAGS is reduced indicates a global increase of lattice distortion and thus an increase of GND. This is quantified in Figure 7(b), showing that the average KAM increases and the distribution widens in subsequent cycles. The widening visualizes the fact that as the grain size

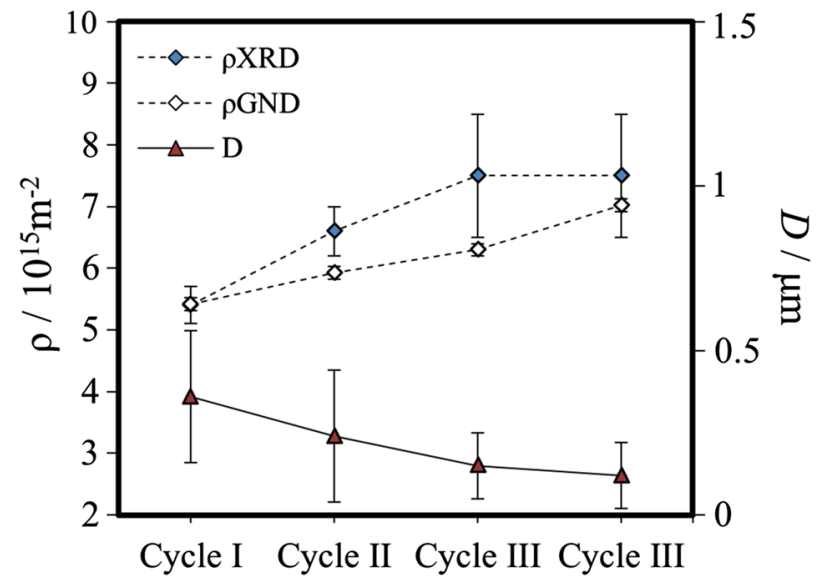

(a)

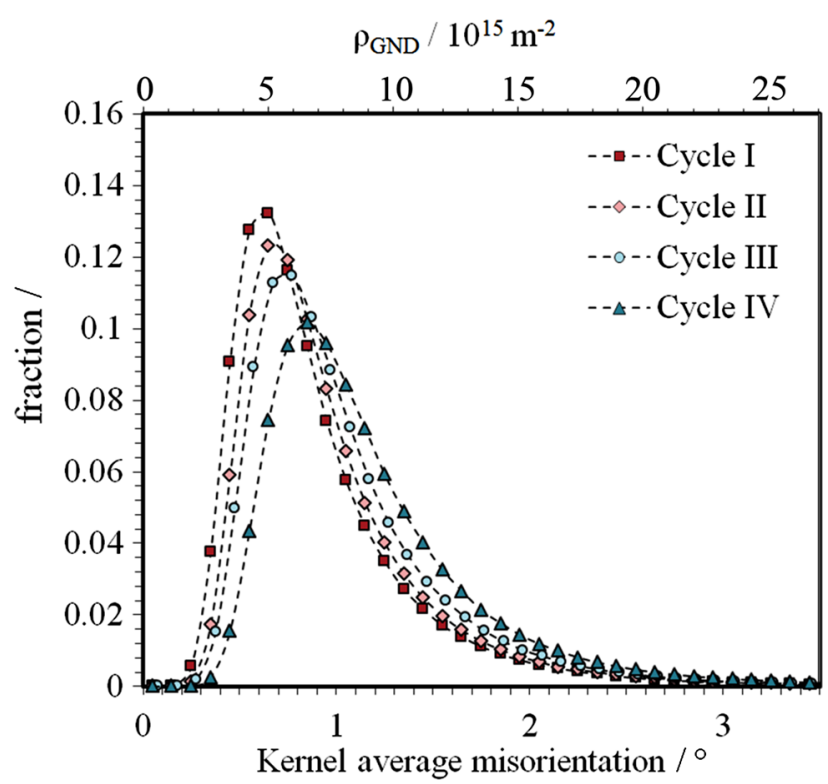

(b)

Fig. 7-(a) Dislocation density calculated by XRD, geometrically necessary dislocation (GND) density and crystalline size as a function of the number of cycles. The errors for GND are estimated in $\pm 10^{-4} \mathrm{~m}^{-2}$. (b) Distribution of KAM of different specimens. The secondary $\mathrm{X}$ axis shows the conversion of $\mathrm{KAM}$ to $\rho_{\mathrm{GND}}$ according to Eq. [1].

decreases, the areas with high strain increase, although still there are regions with low strain levels.

A straightforward estimation of the geometrically necessary dislocation density $\left(\rho_{\mathrm{GND}}\right)$ can be obtained from KAM following Kubin and Mortensen: ${ }^{[28,30]}$

$$
\rho_{\mathrm{GND}}=\frac{1.5 \gamma \vartheta}{u b},
$$

In Eq. [1], the misorientation angle, $\vartheta$, is related with $\rho_{\mathrm{GND}}$ by normalizing with the unit length between points in EBSD scan $u$ (the step size), where $b$ is the Burgers vector and the constant $\gamma$ is dependent on the geometry of the boundaries having values of 2 and 4 for pure tilt or pure twist boundaries, respectively. In the present work, a value of 3 is considered for mixed-type 

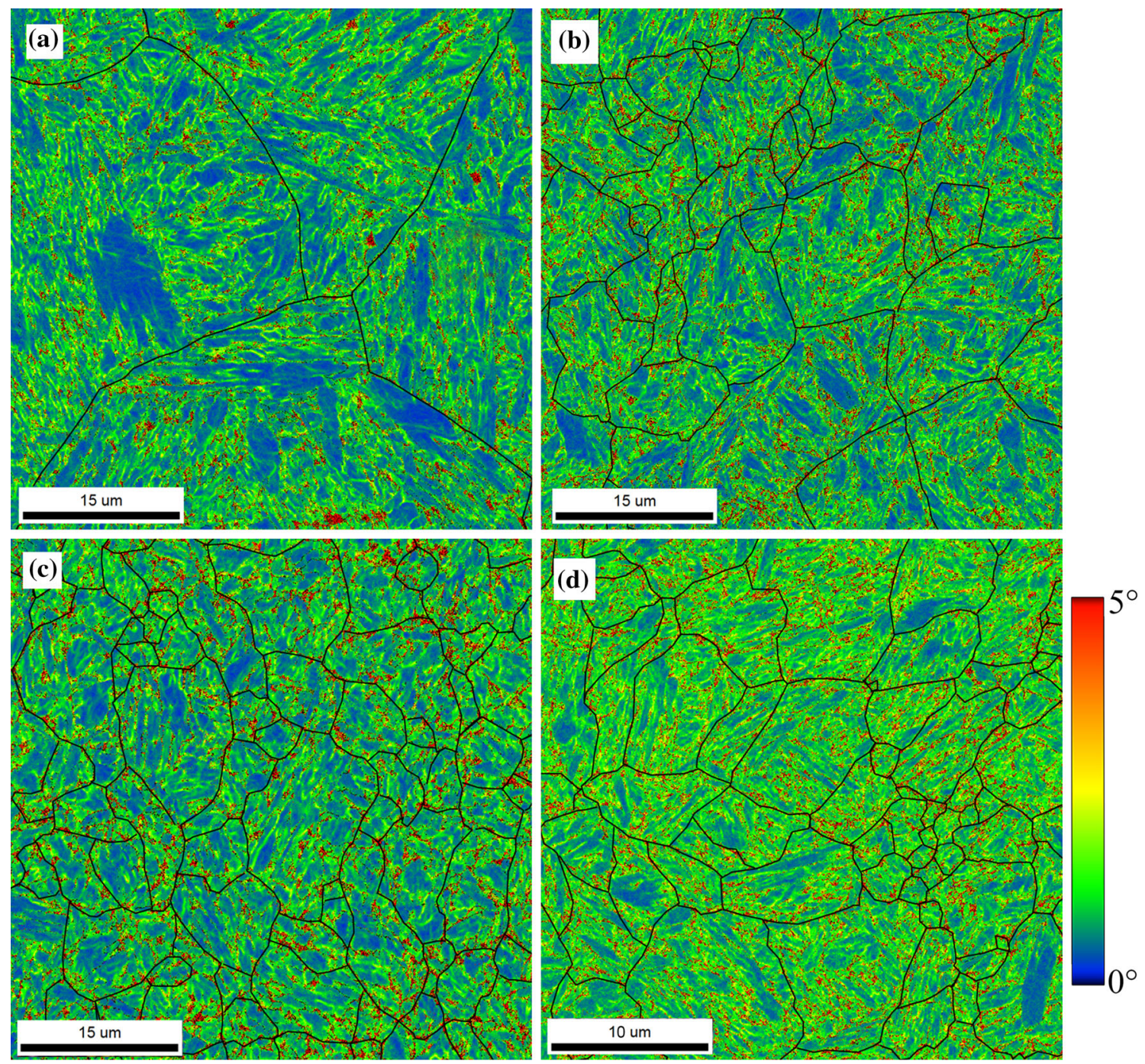

Fig. 8-Kernel average misorientation (KAM) maps of BCC phase after different heat treatments: $(a)$ Cycle I, $(b)$ Cycle II, $(c)$ Cycle III, and $(d)$ Cycle IV. The gradient in color from blue to red corresponds to misorientations (degrees) between 0 deg and 5 deg. Superimposed black lines represent the prior austenite grain boundaries (Color figure online).

boundaries. The dislocation density estimated from KAM only reflects two-dimensional lattice curvatures so that lattice curvature along surface normal direction was ignored. Therefore, $\rho_{\mathrm{GND}}$ may be underestimated and needs to be multiplied by 1.5 . If Eq. [1] is applied to each point of KAM maps, a local value of $\rho_{\mathrm{GND}}$ can be assessed and if those values are averaged for the whole map, a mean $\rho_{\mathrm{GND}}$ can be determined. The method does not yield the global dislocation density, which is better assessed by XRD method, but it is considered good as an estimation of $\rho_{\mathrm{GND}}$ and to evaluate its variations with the number of cycles. Figure 7 shows the variation of $\rho_{\mathrm{GND}}$ with the number of cycles. $\rho_{\mathrm{GND}}$ increases with cycles as it occurred with $\rho_{\text {XRD }}$.

\section{Effect of Cycling on C Redistribution}

Figure 9(a) shows SEM micrographs of the Cycle I specimen. A high density of carbides distributed within the microstructure was developed. These carbides, with a needle-like shape, grow along specific habit planes within block substructures. Different orientations shows the formation of multiple variants. These carbides seem to be more abundant in big blocks. In the case of Cycle II (Figure 9(b)), a high density of carbides is still observable, although needle-shaped carbides seem to dissolve and adopt a more spherical geometry. These carbides are finer compared to the Cycle I specimen. No clear carbide formation is observed in the as-quenched condition of Cycle III and Cycle IV.

X-ray diffraction was used to determine the martensite lattice parameter as explained in Section II. Peak splitting due to tetragonality is not observed and lattice is assumed cubic. Results of lattice parameter, $a_{\mathrm{BCC}}$, are shown in Figure 10. Although some $\mathrm{C}$ will remain in bcc phase, the reference specimen is assumed to have negligible fraction of $\mathrm{C}$ in solid solution. $a_{\mathrm{BCC}}$ of Cycle I was quite close to the reference specimen, thus $a_{\mathrm{BCC}}$ in this and Cycle I specimens is less affected by carbon. Subsequently, $a_{\mathrm{BCC}}$ increases significantly in Cycle II, 

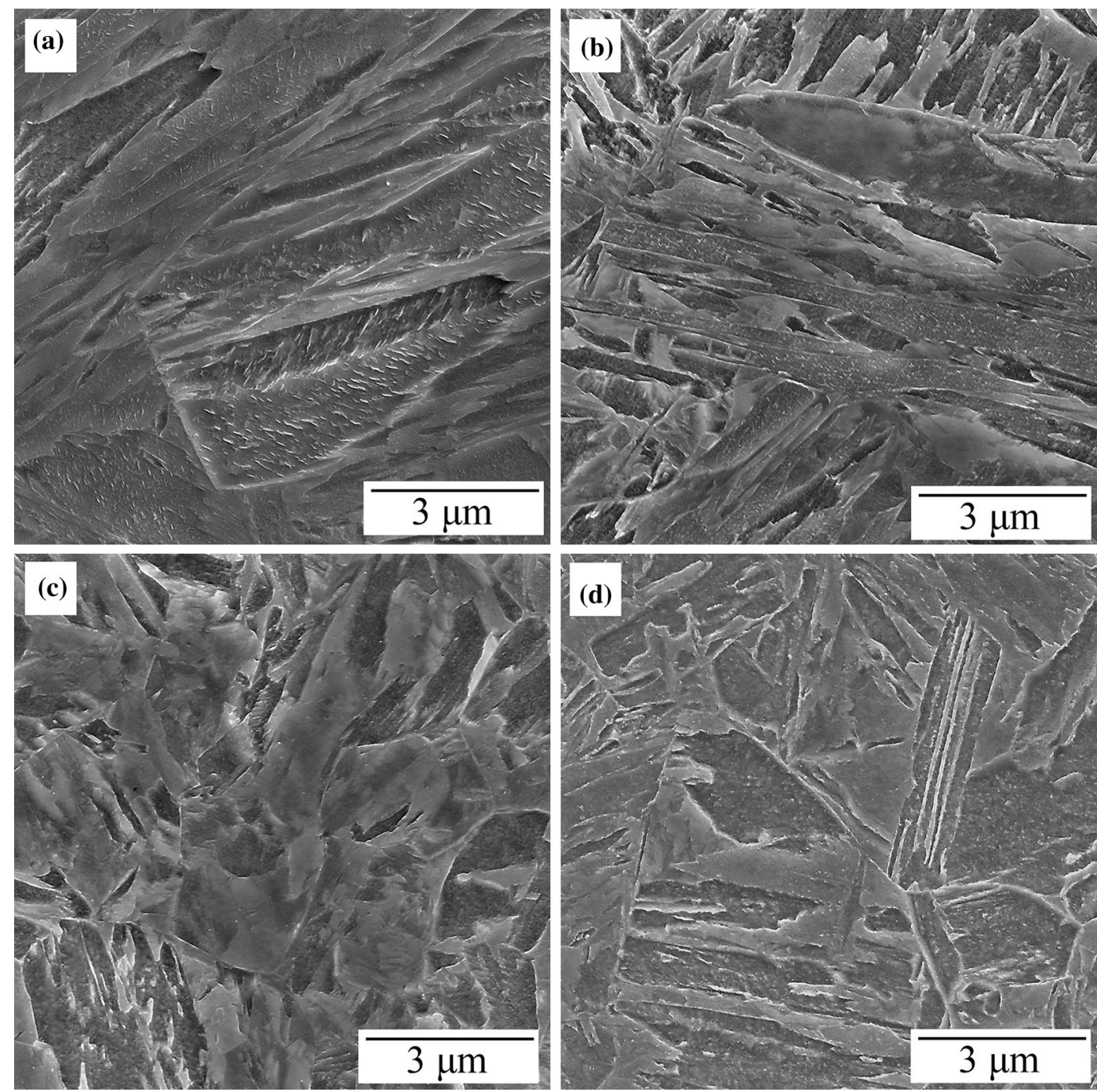

Fig. 9-SEM secondary electron mode images showing the resulting microstructure after different cycles: $(a)$ Cycle I, (b) Cycle II, (c) Cycle III, and $(d)$ Cycle IV.

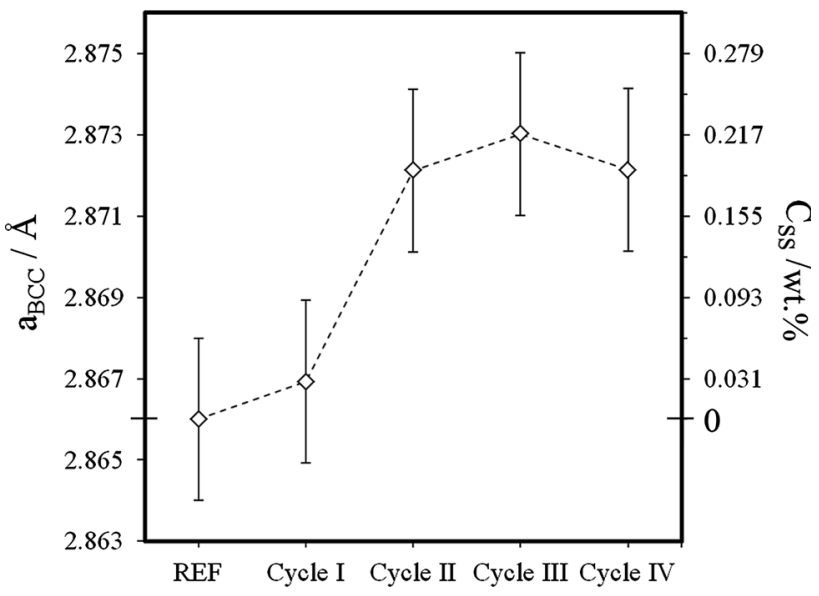

Fig. 10-Variation of lattice parameter and $\mathrm{C}$ concentration in solid solution with the number of cycles. The values measured with the reference sample are also plotted. but varies insignificantly in subsequent cycles. This change of lattice parameter is suggesting that there is more $\mathrm{C}$ in solution after quenching in Cycle II and subsequent cycles specimens. Assuming that the variation of the lattice parameter, $\Delta a$, is only caused by the concentration of $\mathrm{C}$ in solid solution, $C_{\mathrm{SS}}$, the solute carbon concentration, can be determined by considering independent calibration data according to Reference 31

$$
C_{\mathrm{SS}}=31(\text { wt pct } / \AA) \times \Delta a .
$$

According to Eq. [2], except for the Cycle I specimen, the values of $C_{\mathrm{SS}}$ obtained (see Figure 10(a)) are lower but close to the overall concentration $0.3 \mathrm{wt}$ pct of the alloy. $C_{\mathrm{SS}}$ of Cycle I specimen is low compared to the rest of the cycles. These results are consistent with the apparently lower density of carbides in Cycle II-IV compared to Cycle I. 


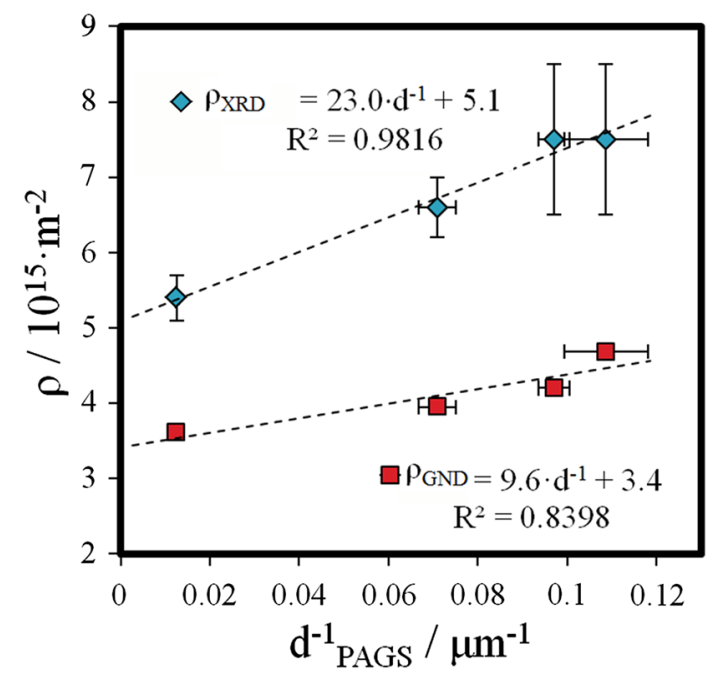

(a)

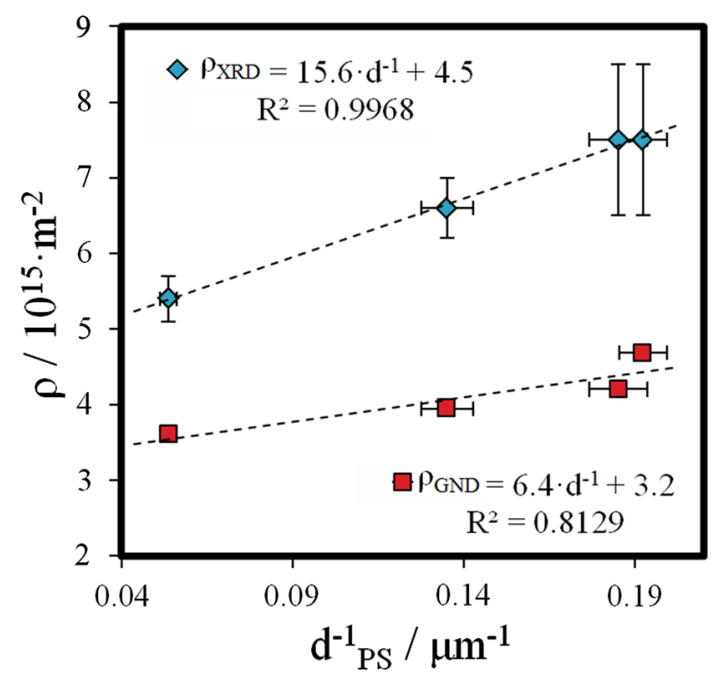

(b)

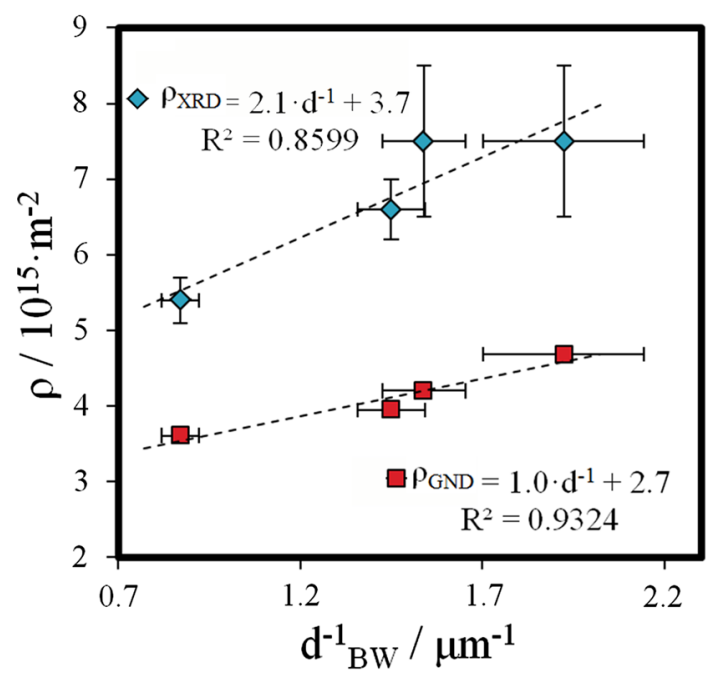

(c)

Fig. 11-Relations between dislocation densities and the inverse of grain substructures sizes: (a) PAGS), (b) PS, and (c) BW.

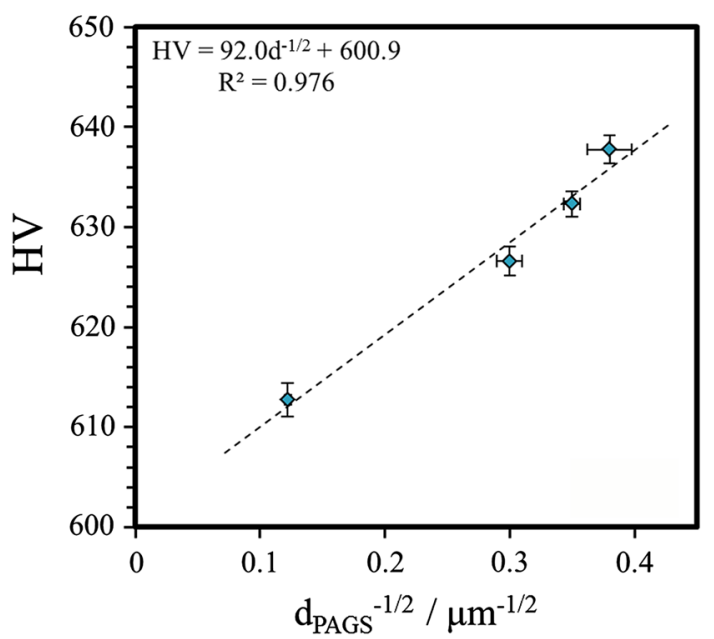

(a)

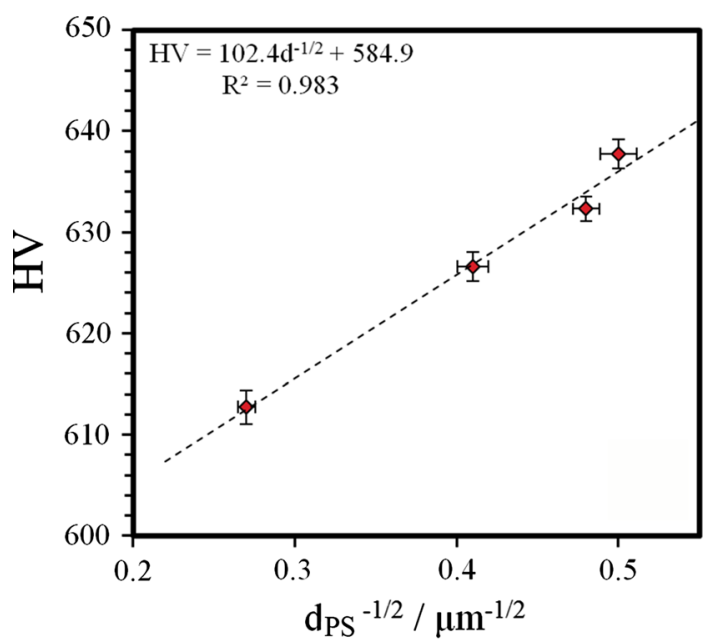

(b)

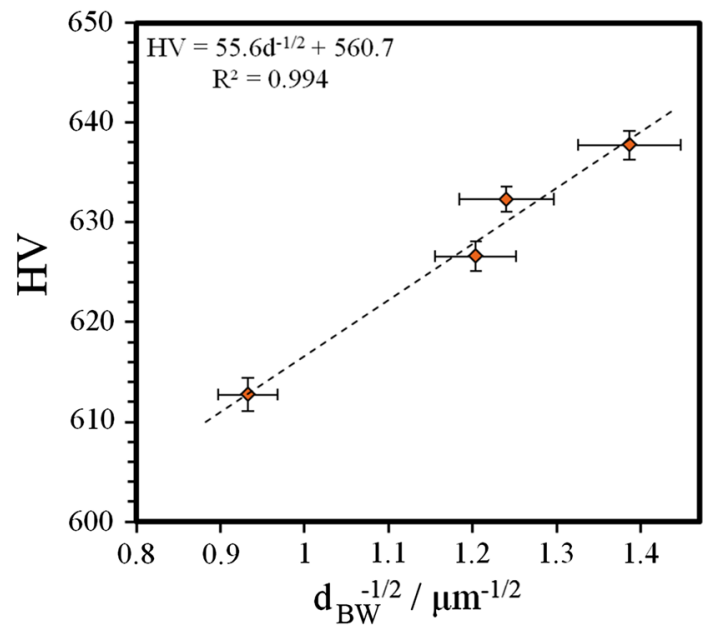

(c)

Fig. 12-Hardness as a function of the square root of the inverse of grain substructure size, (a) PAGS, (b) PS, and (c) BW. Dashed line represent a linear fitting according to theoretical Hall-Petch relation, Eq. [3]. 


\section{DISCUSSION}

\section{A. Effect of Thermal Cycling on Grain Substructures}

Some of the earliest references of the use of thermal cycling to reduce the austenite grain size can be found in the work of Grange. ${ }^{[15]}$ This author successfully applied this technique to a variety of steels, obtaining a reduction of austenite grains down to few micrometer. Since then, thermal cycling processes have been investigated in a number of studies. ${ }^{[3,5,14,16]}$ These studies highlight that microstructure refinement can be achieved effectively by successive $\alpha^{\prime} \rightarrow \gamma$ reversion processes involving rapid heating. This is also the conclusion of the present study. The reduction of PAGS is particularly effective in the first cycle. In subsequent cycles, the reduction is less obvious and a constant value of PAGS can be assumed for more than four cycles. This phenomenon is common in all literature consulted. Grange ${ }^{[15]}$ concluded that this eventual grain size is independent of the initial grain size if the same heat treatments are employed, but it is influenced by alloy composition. For example, this author obtained a refinement up to around $11 \mu \mathrm{m}$ in a $0.2 \mathrm{C}-2 \mathrm{Mn}$ steel. This value is similar to the one achieved with the present steel. An increase of the density of austenite nuclei formed above $\mathrm{A}_{\mathrm{cl}}$ as the austenite grain size becomes smaller after each preceding cycle may explain grain refinement during first cycles. ${ }^{[15]}$ However, when a critical austenite grain size is achieved, austenite becomes unstable and rapid grain growth prevents additional refinement.

The reduction of PAGS through cycles resulted in smaller martensite packets and blocks. Takaki et al. pointed out that as PAGS is reduced, the number of variants forming during martensitic transformation is reduced. ${ }^{[32]}$ This agrees with current observations in martensitic steel. The number of packets per parent austenite grain is reduced with decreasing PAGS as well as the ratio $d_{\mathrm{PAGS}} / d_{\mathrm{PS}}$, which approaches unity. Furuhara et al..$^{[3]}$ observed a similar behavior in an Fe-0.2C-2Mn steel for a PAGS smaller than $50 \mu \mathrm{m}$. In Cycle III and Cycle IV, some PAGSs are still sub-divided into a few packets, even in austenite grains of few micrometer, but it was common to observe a single packet being formed in an austenite grain for PAGS around one micrometer.

Kim et al. ${ }^{[6]}$ noticed that rapid reversion treatments break-up the alignment of blocks in packets to create ultrafine-grained martensite. This fact is also observed in the present study. A change in morphology occurs when the PAGS is reduced. Elongated and parallel distributed blocks mainly formed within coarse packets. These also show a high aspect ratio. On the contrary, blocks were rounded and more randomly distributed in finer packets developed in Cycle III and Cycle VI. No preferential direction of blocks is developed from cycling, in contrast with the observations of Kim. ${ }^{[6]}$

\section{B. Effect of Grain Substructures on Dislocation Density}

Both $\rho_{\mathrm{XRD}}$ and $\rho_{\mathrm{GND}}$ increase with the consecutive cycles. In all specimens, the order of magnitude of the measured dislocation densities is $10^{15} \mathrm{~m}^{-2}$, which is a typical value for as-quenched lath martensite. ${ }^{[23]} \rho_{\mathrm{XRD}}$ of the reference sample $\left(6 \times 10^{13} \mathrm{~m}^{-2}\right)$ was two orders of magnitude less than for as-quenched conditions. The reference sample was reheated to just below the intercritical region and subsequently quenched, which suggests that in the specimens treated by thermal cycling most of the dislocations were recovered during martensite the reversion process of different cycles and regenerated during quenching.

Figure 11 shows a plot of the dislocation density assessed by XRD and KAM vs the inverse of grain substructure sizes. In all cases, linear relations can be drawn in which dislocation density increases as the grain size is reduced. Similar trends were observed by Kennett ${ }^{[13]}$ in low-C microalloyed lath martensite steel when the dislocation density were compared with the PAGS.

It can be assumed that block growth is controlling the strain development in surrounding regions and thus controlling $\rho_{\mathrm{GND}}$. Nonetheless, packets and prior austenite boundaries are limiting frontiers to block growth, which would explain that all substructures show, to some extent, an inverse relation with $\rho_{\mathrm{GND}}$. As the PAGS is reduced, the austenite is most likely strengthened and the martensite has to overcome higher shear stresses during its formation, which requires a development of higher density of dislocations to accommodate plastic strain. All these factors can play a role in the relations of dislocation density with grain sizes.

\section{Effect of Grain Substructures in Auto-Tempering and C Distribution}

$\mathrm{C}$ diffusion during quenching occurs in low-alloy carbon steels with $M_{\mathrm{S}}$ above room temperature. ${ }^{[27]}$ The carbides formed in some of the cycles are likely formed due to auto-tempering, i.e., tempering taking place during the quenching process and resulting in carbide precipitation.

Several authors ${ }^{[33,34]}$ observed that carbides precipitate in coarse as-quenched martensite due to an auto-tempering effect, while fine martensite lath remained free of carbides. Morito et al. ${ }^{[35]}$ described needle-like morphology of carbides in low-C temper lath martensite similar to the one observed in the Cycle I specimen. However, they reported a lack of carbides in the as-quenched conditions. In previous work with the same alloy and grain sizes comparable to Cycle III and Cycle IV specimens, HajyAkbary et al. ${ }^{[23]}$ obtained similar needle-like carbides morphologies after tempering as-quenched specimens at $673 \mathrm{~K}\left(400{ }^{\circ} \mathrm{C}\right)$ during different times; no clear carbide formation was detected in the as-quenched condition. The no observation of carbides in Cycle III and Cycle IV, and the carbon concentrations in martensite below the expected for the alloy suggest that $\mathrm{C}$ segregates to defects sites like dislocations. By site specific atom probe tomography analysis, several authors observed $\mathrm{C}$ segregations in dislocations rather than precipitates in lath martensite steels. ${ }^{[31,34]}$

Comparing these results with results in this study, it is concluded that coarse PAGSs promote the auto-tempering and develop more prominent carbides 
in comparison to less effective carbide formation in finer grains.

It is known that auto-tempering is most likely occurring in steels with high $M_{\mathrm{S}} \cdot{ }^{[36]} M_{\mathrm{S}}$ is lowered with reduction of PAGS due to cycling and can be influencing $\mathrm{C}$ diffusion after martensite formation during cooling. It is worth to note that big blocks, which show the lowest KAM values in Cycle I, are related to regions in which carbides appear more prominently in SEM observations. Morsdorf et al. ${ }^{[34]}$ also observed that coarse martensite blocks are more auto-tempered with $\mathrm{C}$ segregating to plate-like defect in comparison to thin martensite blocks, which segregate to 1D structures. They correlated coarse laths to the first formed during transformation and suggested that they dwells more time at higher temperatures than finer laths former near $M_{\mathrm{f}}$.

The higher boundary and dislocation densities measured as the PAGS decreases will facilitate $\mathrm{C}$ redistribution during auto-tempering. Less density of dislocations observed in Cycle I specimen will lead to a higher concentration of $\mathrm{C}$ segregated from martensite to these sites, resulting in bigger carbide precipitates. Both, lower $M_{\mathrm{S}}$ and higher density of dislocations will contribute to a refinement of carbides due to less accessible $\mathrm{C}$ when this element migrates from interstitial positions during auto-tempering.

\section{Hardness Measurements}

To contrast all the results obtained in microstructure characterization, hardness measurements are performed. Hardness values as a function of the square root of the inverse of different grains substructure size are plotted in Figure 12. The dashed lines correspond to the fitting to Hall-Petch relation as described in Eq. [3], where $d$ represents the grain size, $K$ is the strengthening factor, and $H V_{0}$ is a constant depending on the material.

$$
H V_{i}=H V_{0}+K d^{-\frac{1}{2}}
$$

A Hall-Petch relation is observed in all cases, but small variation of hardness suggests a weak influence of grain substructure size. These values are similar to those obtained by Hutchinson et al. ${ }^{[31]}$ for a 0.31 wt pet $\mathrm{C}$ martensitic steel. In their work, Hutchinson et al. also realized that the contribution of grain refinement accounts for only a small amount of the strength of the martensite and pointed out to a greater influence of $\mathrm{C}$ on strength. However, the reasons for high hardness and its dependence on total $\mathrm{C}$ content in martensite are still uncertain. In one hand, the $\mathrm{C}$ content in martensite in Cycle I is much lower than in the other specimens, but differences in hardness with respect other specimens are small. On the other hand, a similar $\mathrm{C}$ in solid solution is measured from Cycle II, but the hardness, although slightly, increases with the number of cycles. The measured hardness does not depend exclusively on the contribution of $\mathrm{C}$ and segregations or precipitates formed, but from interrelations observed between grain substructure size, dislocation density, and C distribution. These interrelations will be investigated in a future research, in which a more detailed evaluation of mechanical properties will be carried out.

\section{E. Influence of PAGS on Martensite Transformation}

The $M_{\mathrm{S}}$ of the present steel is lowered as the PAGS is reduced due to thermal cycling. This fact is extensively observed in steels. Several qualitative explanations of these observations have been offered. ${ }^{[1]}$ Most of them coincide with a strengthening of the austenite as PAGS is reduced; however, the source of this strengthening is unclear. Ansell and his co-workers ${ }^{[37]}$ first proposed a Hall-Petch phenomenon as a plausible strengthening mechanism of austenite. The local strength of austenite would determine the resistance against plastic deformation and thus the strain energy involved in the formation of laths of martensite. Thus, when the resistance of austenite to plastic deformation is locally reduced, the transformation can occur at higher temperatures. The results obtained during the present study also points to an strengthening of austenite with a reduction of the PAGS, which determines the manner in which martensite is formed influencing final microstructure.

Lee $^{[38]}$ observed an increase of dislocation density in austenite at temperatures above $M_{\mathrm{S}}$ after application of austenite-martensite reversion cycles in a Fe-17Mn alloy. An increase of dislocation density introduced into austenite can lead to an increase of shear stress and thus a reduction of $M_{\mathrm{S}}$. In the present work, accumulation of dislocations in consecutive cycles is uncertain. The dislocation density in martensite increases as PAGS decreases. It can be presumed that the recovery of dislocations during the reversion process of the more dislocated martensite will be less effective. Consequently, the dislocation density of newly formed austenite will increase, contributing to the strengthening of austenite grains.

Takaki $^{[32]}$ explained austenite stabilization with refinement of grain size by the increasing difficulty of multivariant transformation. Unlike coarse grains in which multivariant blocks form to minimize the local shear distortion accompanied with the martensitic transformation, in fine PAGs, the relaxation of volume expansion is not enough and the elastic strain energy becomes large. The compensation of this elastic strain energy by chemical-free energy is required for nucleation of martensite, which in turn results in higher undercooling. As discussed previously in Section IV-A, multivariant growth is still observed in the finest grains, although the number of variants per parent austenite grain decreases. Reduction of PAGS due to cycling may be insufficient to achieve single variant transformation, but the observed increase of strain levels may be a consequence of restriction of variants as discussed in Reference 32.

Van Bohemen and Sietsma ${ }^{[10]}$ realized that the PAGS does not have an effect on the global kinetics of martensite formation, but only in the first stages up to certain volume fraction. Fisher et al. proposed that the volume fraction of martensite formed in the early stages 
of transformation is proportional to the cube of the austenite grain size. ${ }^{[1]}$ KAM maps reveal heterogeneities that bring to light how martensite is formed. Regions with very low KAM (less strained) are related to first substructures to nucleate from parent austenite grain, as discussed in Section III-C. As the first martensite nucleates, the volumetric change accompanying transformation has to be accommodated by the surroundings that present higher KAM values. This austenite to martensite transformation sequence was also recently proposed by Morsdorf et al. ${ }^{[34]}$ after investigations with a $0.13 \mathrm{C}-5.1 \mathrm{Ni}$ steel. In Reference 10 , it is suggested that the first-formed martensite laths from coarse PAGs have a relatively strong stabilization effect in the remaining retained austenite, most likely due to a relatively high aspect ratio. This matches with the current observations in coarse PAGs. It seems that the fractions of those less strained regions and the aspect ratio of martensite blocks are reduced with the number of cycles and the refinement of PAGS.

The RA fractions also increase with reduction of PAGS, although slightly. This agrees with transformation stabilization-induced mechanisms governing the kinetics of martensite formation. It is reasonable to assume that PAGs, packets, and blocks boundaries are limiting frontiers to newly formed martensite growth and thus the latest zones to transform, with high strain concentration. Hence, an increase of the grain boundary density should result in higher fractions of RA if the undercooling is not sufficient to promote transformation.

\section{CONCLUSIONS}

The application of thermal cycling to a $0.3 \mathrm{C}$ 1.5Si-3.5Mn steel was shown to be effective in reducing the PAGS which led to the following effects in the microstructure:

- The size of PAGSs, packets, and blocks decreased more effectively after first cycles, but their size distribution tended to homogenize with the number of cycles. This led to the observation of an increase in the density of high misorientation grain boundaries with the number of cycles.

- The number of variants per parent austenite grain was reduced and the morphology of the packets and blocks rounds as the PAGS is reduced.

- The dislocation density in martensite increased with decreasing PAGS and followed an inverse relation with the martensite grain substructure sizes which can be explained by an increase of prior austenite strengthening.

- Locally, the distribution of GNDs was found to be heterogeneous, showing low-strained substructures surrounded by highly strained regions. This suggested the early growth of some preferential blocks, which forces the surroundings to accommodate the resulting volume expansion.

- The carbon concentration in solid solution increased and carbides were refined as PAGS was reduced.
The combination of a higher dislocation density and a reduction of $M_{\mathrm{S}}$ as PAGS was reduced affect the auto-tempering and thus the carbon redistribution and carbide formation.

- Slight variation of hardness with grain size is observed, although Hall-Petch relations are observed in all grain substructures. The reasons for high hardness and its dependence on total $\mathrm{C}$ content in martensite, dislocation density, and grain size are still uncertain. This will be further investigated in a future work.

- As the PAGS was refined, the Ms lowered and slightly higher austenite fractions were retained at room temperature. This is related with prior austenite strengthening by different mechanisms and the need of a higher undercooling to compensate the elastic strain energy by chemical-free energy in order to promote nucleation of martensite.

The present work demonstrates that the manner in which martensite forms, influenced by the strengthening of prior austenite and reduction of available variants as the size is reduced during thermal cycling, has a strong effect on different interrelated microstructural features.

\section{ACKNOWLEDGMENTS}

The authors want to acknowledge Jilt Sietsma and R. Huizenga from TU Delft as well as R. Petrov and F.C. Cerda from Ghent and Delft University for their help and wise advice for the present work. The research leading to these results has received funding from the European Research Council under the European Union's Seventh Framework Programme (FP/ 2007-2013) / ERC Grant Agreement n. [306292].

\section{OPEN ACCESS}

This article is distributed under the terms of the Creative Commons Attribution 4.0 International License (http://creativecommons.org/licenses/by/4.0/), which permits unrestricted use, distribution, and reproduction in any medium, provided you give appropriate credit to the original author(s) and the source, provide a link to the Creative Commons license, and indicate if changes were made.

\section{REFERENCES}

1. S. Morito, X. Huang, T. Furuhara, T. Maki, and N. Hansen: Acta Mater., 2006, vol. 54, pp. 5323-31.

2. S. Morito, H. Tanaka, R. Konishi, T. Furuhara, and T. Maki: Acta Mater., 2003, vol. 51, pp. 1789-99.

3. T. Furuhara, K. Kikumoto, H. Saito, T. Sekine, T. Ogawa, S. Morito, and T. Maki: ISIJ Int., 2008, vol. 48, pp. 1038-45.

4. T. Hanamura, S. Torizuka, S. Tamura, S. Enokida, and H. Takechi: ISIJ Int., 2013, vol. 53, pp. 2218-25.

5. W. Hui: Microstructure Refining and Strengthening of Martensitic Steel, incl. in Ultra-Fine Grained Steels, Springer Berlin Heidelberg, 2009, pp. 300-49. 
6. H.J. Kim, Y.H. Kim, and J.W. Morris, Jr: ISIJ Int., 1998, vol. 38, pp. $1277-85$.

7. J.W. Morris, Jr: ISIJ Int., 2008, vol. 48, pp. 1063-70.

8. Y. Mine, K. Hirashita, H. Takashima, M. Matsuda, and K. Takashima: Mater. Sci. Eng. A, 2013, vol. 560, pp. 535-44.

9. T. Ohmura and K. Tsuzaki: Mater. Sci. Forum, 2005, vols. 475-479, pp. 4113-16.

10. S.M.C. Van Bohemen and J. Sietsma: Mater. Sci. Technol-Lond., 2014, vol. 30, pp. 1024-33.

11. H.S. Yang and H.K.D.H. Bhadeshia: Scripta Mater., 2009, vol. 60 , pp. 493-95.

12. F. Maresca, V.G. Kouznetsova, and M.G.D. Geers: J. Mech. Phys. Solids, 2014, vol. 73, pp. 69-83.

13. S.C. Kennett, G. Krauss, and K.O. Findley: Scripta Mater., 2015, vol. 107 , pp. 123-26.

14. B.H. Chapman, M.A. Cooke, and S.W. Thompson: Scripta Metall. Mater., 1992, vol. 26, pp. 1547-52.

15. R.A. Grange: Metall. Trans., 1971, vol. 2, pp. 65-78.

16. L.F. Porter and D.S. Dabkowski: Ultrafine-Grain Metals, Syracuse University Press, Syracuse, 1970.

17. H.S. Yang and H.K.D.H. Bhadeshia: Mater. Sci. Tech. Ser., 2007 , vol. 23, pp. 556-60.

18. S.M.C. Van Bohemen: Scripta Mater., 2013, vol. 69, pp. 315-18.

19. L. Zhao, N.H. Van Dijk, E. Brück, J. Sietsma, and S. Van Der Zwaag: Mater. Sci. Eng. A, 2001, vol. 313, pp. 145-52.

20. H. Abrams: Metallography, 1971, vol. 4, pp. 59-78.

21. B. D. Cullity: Elements of X-Ray Diffraction, Addison-Wesley Publishing Co., Reading, 1958.

22. M.U. Cohen: Rev. Sci. Instrum., 1935, vol. 6, pp. 68-74.

23. F. HajyAkbary, J. Sietsma, A.J. Böttger, and M.J. Santofimia: Mater. Sci. Eng. A, 2015, vol. 639, pp. 208-18.
24. T. Karthikeyan, M.K. Dash, S. Saroja, and M. Vijayalakshmi: Micron, 2015, vol. 68, pp. 77-90.

25. P.P. Suikkanen, C. Cayron, A.J. DeArdo, and L.P. Karjalainen: $J$. Mater. Sci. Technol., 2011, vol. 27, pp. 920-30.

26. J. Pešička, R. Kužel, A. Dronhofer, and G. Eggeler: Acta Mater., 2003, vol. 51, pp. 4847-62.

27. G. Krauss: Mater. Sci. Eng. A, 1999, vols. 273-275, pp. $40-57$.

28. M. Calcagnotto, D. Ponge, E. Demir, and D. Raabe: Mater. Sci. Eng A, 2010, vol. 527, pp. 2738-46.

29. D.A. Hughes, N. Hansen, and D.J. Bammann: Scripta Mater., 2003, vol. 48, pp. $147-53$.

30. L.P. Kubin and A. Mortensen: Scripta Mater., 2003, vol. 48, pp. 119-25.

31. B. Hutchinson, J. Hagström, O. Karlsson, D. Lindell, M. zTornberg, F. Lindberg, and M. Thuvander: Acta Mater., 2011, vol. 59 , pp. $5845-58$.

32. S. Takaki, K. Fukunaga, J. Syarif, and T. Tsuchiyama: Mater. Trans., 2004, vol. 45, pp. 2245-51.

33. R.W. Fonda and G. Spanos: Metall. Trans. A, 2014, vol. 45, pp. 5982-89.

34. L. Morsdorf, C.C. Tasan, D. Ponge, and D. Raabe: Acta Mater., 2015, vol. 95, pp. 366-77.

35. S. Morito, T. Ohba, A.K. Das, T. Hayashi, and M. Yoshida: ISIJ Int., 2013, vol. 53, pp. 2226-32.

36. H.K.D.H. Bhadeshia and S.R. Honeycombe: 9-The Tempering of Martensite, incl. in Steels (Third Edition), Butterworth-Heinemann, Oxford, 2006, pp. 183-208.

37. P.J. Brofman and G.S. Ansell: Metall. Trans. A, 1983, vol. 14A, pp. 1929-31.

38. Y.K. Lee: Metall. Trans. A, 2002, vol. 33, pp. 1913-17. 